\title{
Experimental research of liquid-fueled continuously rotating detonation chamber
}

\author{
P. Wolański ${ }^{1}$ (D) W. Balicki ${ }^{1}$ (D) W. Perkowski ${ }^{1}$ (i) $\cdot$ A. Bilar ${ }^{1}$ (i)
}

Received: 1 December 2019 / Revised: 26 March 2021 / Accepted: 1 May 2021 / Published online: 5 June 2021

(c) The Author(s) 2021

\begin{abstract}
Research on the application of liquid fuels to continuously rotating detonation was conducted. A new method of mixture preparation was proposed. A special system of liquid fuel injection was designed and tested which is based on injecting into the detonation chamber a preheated liquid fuel partially mixed with hot air at conditions higher than the rich flammability limit. The specially selected conditions allow all liquid fuel to evaporate in the supply system but prevent it from ignition before entering the detonation chamber. Experiments were conducted for two different liquid fuels, extraction gasoline and Jet-A fuel. Research was carried out for different equivalence ratios, and in all tested conditions detonation was achieved. The new tested method of liquid fuel preparation and injection into a cylindrical detonation chamber opens a way of application of liquid fuels to engines which utilize continuously rotating detonation and thus prepares the way for practical application of detonative combustion to turbine engines and jet propulsion systems.
\end{abstract}

Keywords Rotating detonation $\cdot$ Detonation $\cdot$ Liquid fuel

\section{Introduction}

The most important development needed for successful application of continuously rotating detonation to propulsion systems is to achieve operation of such engines with liquid jet fuels. First such attempts were carried at the University of Michigan [1, 2]. Many attempts made in these directions have not been successful yet, however, research is being continuously conducted in many different laboratories [3]. There are a few basic requirements needed to obtain a successful operation of a combustion chamber supplied with liquid aviation fuel. One of the most important conditions is a very good atomization of the liquid fuel and rapid evaporation of droplets. Additionally, the fuel-mixture has to be uniform and the dimension of the detonation channel should also be relatively large. Operation at elevated pressure is usually helpful, since the detonation cell size is smaller for higher initial pressure, so for higher initial pressure, the size of the

Communicated by E. Gutmark.

P. Wolański

piotr.wolanski@ilot.lukasiewicz.gov.pl

1 Łukasiewicz Research Network - Institute of Aviation, Warsaw, Poland detonation chamber in which detonation can stably propagate can also be smaller. All these conditions are very difficult to fulfill, and up to now successful, stable continuously rotating detonation in an annular chamber for atmospheric conditions of jet fuel-air mixtures has not been achieved. Unstable detonation of a jet fuel-air mixture was already achieved at the Institute of Aviation in Warsaw, but not all atomized fuel was consumed in the rotating detonation and the efficiency of such combustion processes was relatively low [4-6]. The aim of this research was to prepare a uniform fuel-air mixture which eventually would allow stable detonation of a liquid fuel-air mixture in a chamber of reasonable size and under initial atmospheric conditions. Thus, a special system was developed which is now subject of a patent application [7].

\section{Experimental test stand for continuously rotating detonation}

Experiments were conducted in an adapted annular detonation chamber used in previous studies [6] with a newly designed fuel supply and injection system, in which fuel was evaporated and mixed with hot air. The amount of air used as fuel vapor carrier was very small and at a 
composition above the flammability limit. Such a fuel supply system guarantees injection of unreacted but evaporated fuel into the main chamber. Details of this newly invented system are described in the patent application [7]. Main air, preheated to about $100{ }^{\circ} \mathrm{C}\left( \pm 5^{\circ} \mathrm{C}\right)$, was supplied at a carefully controlled rate to the detonation chamber from a high-pressure installation. Upstream of the annular detonation chamber (Fig. 1), a pitot tube was used to measure air velocity and a thermocouple to measure the air temperature. Injectors of a rich fuel-air mixture were located just before the detonation chamber. This mixture was prepared in a special mixing supply line where liquid fuel preheated to $160{ }^{\circ} \mathrm{C}\left( \pm 10^{\circ} \mathrm{C}\right)$ was mixed with high pressure air preheated to $100{ }^{\circ} \mathrm{C}\left( \pm 10{ }^{\circ} \mathrm{C}\right)$, which was supplied from a $2-\mathrm{m}^{3}$ high-pressure tank. The pressure in the tank was up to 6 bar and was dropping to about 5 bar during 4-s tests. The fuel supply rate was constant during each test, but the air supply rate was always decreasing, since the pressure in the tank was also decreasing. For this reason, the equivalence ratio of the mixture in the annular destination chamber was varying from lean, at the beginning of the test, to rich at the end of the test. Both liquid fuel and air supply rate were very carefully monitored, since the injected rich fuel-air mixture should always be above the flammability limit. Fuel supply rate was calculated on the basis of pressure in the fuel tank (previously calibrated), and the high-pressure air mass flow was calculated using a venturi tube as well as pressure and temperature measurements. Pressure was measured by Kobold SEN transducers and temperature by $\mathrm{NiCr}-\mathrm{Ni}$ (type $\mathrm{K})$ thermocouples. It was also very important to keep all parameters under very tight control to allow liquid fuel to evaporate completely but simultaneously to prevent it from cracking. To reach such conditions not only temperature of both air and liquid fuel needs to be under strict control, but also the residence time of the created very rich mixture in the mixing chamber should be properly adjusted. For this reason, the length of rich mixture supply lines which connect the mixing chamber with the detonation chamber was about $0.6 \mathrm{~m}( \pm 20 \mathrm{~cm})$, depending on the injection point. The thus-created very rich mixture was injected into the main stream of air just before the critical section of the annular detonation chamber (Fig. 2). The rich fuel-air mixture was injected by 90 holes, each with a diameter of $1 \mathrm{~mm}$. The annular detonation chamber with an inner diameter of $225 \mathrm{~mm}$, is equipped with pressure sensors as well as a special ignition system which consists of a high-energy electrical spark. Additionally, an open flame was placed at the end of the annulus chamber to ensure ignition of mixture leaving the chamber in the case when an electrical spark was not sufficient to ignite the mixture in the detonation chamber. For pressure measurements

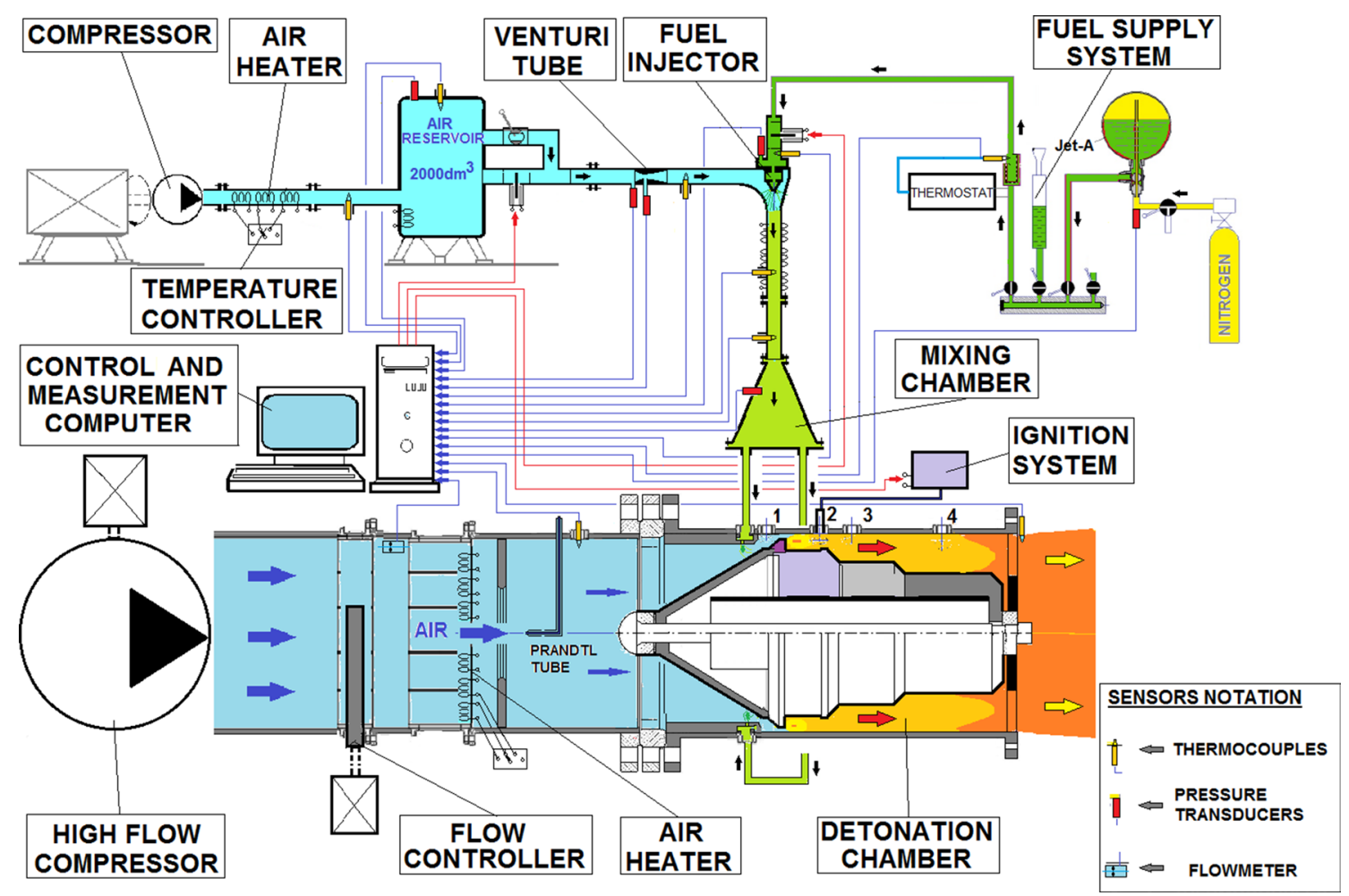

Fig. 1 Schematic diagram of experimental test stand with fuel supply system. Designation of signals entering and leaving the control computer: blue lines—-signals from sensors; red lines—signals controlling the solenoid valves and the ignition system 


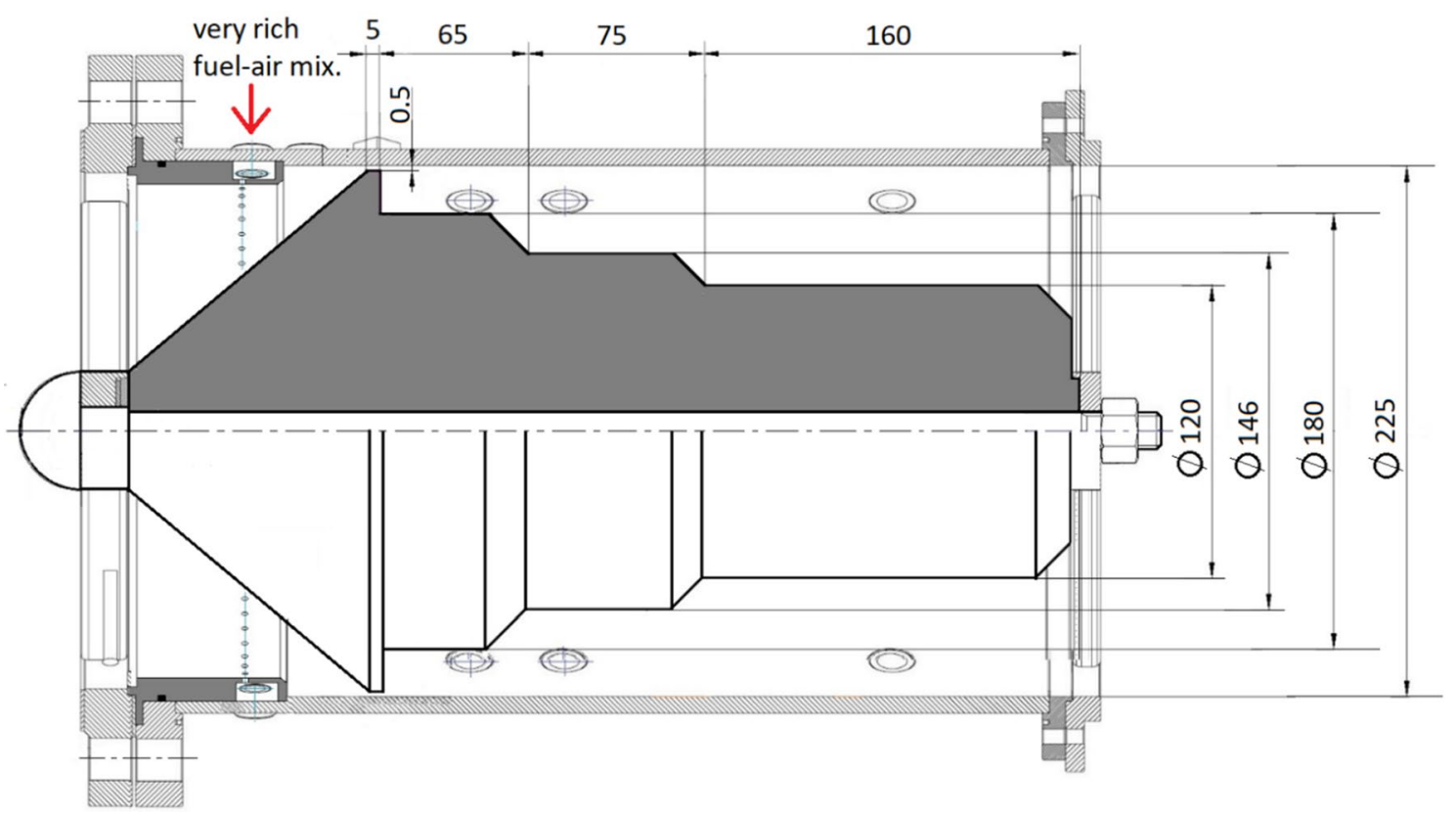

Fig. 2 Details of the annular detonation chamber

a high-frequency quartz pressure sensor Kistler 603B was used. Possible locations of pressure transducers are indicated in Fig. 1 by numbers 1 to 4 . Since tests usually lasted a few seconds all used transducers were protected by a relatively thick layer of silicon grease. This modified the output of the transducer (usually a much lower pressure was indicated), so pressure measurements were only indicative of the shape of pressure variations as well as the frequency of wave rotations. Such measurements allow only to measure wave rotation velocity and possible numbers of detonation waves. To conduct experiments, the main air flow rate and temperature are adjusted, and then rich fuel-air mixture is injected to the main chamber and ignition is initiated. The conducted experiments usually last between 1 and $4 \mathrm{~s}$, and the process is controlled by a PC computer. All data are recorded by a Data Acquisition System (DAS) and stored in a PC computer. Before each experiment the main air flow heated to $100{ }^{\circ} \mathrm{C}$ was initiated for at least one minute to allow the detonation chamber to warm. To start the test simultaneously a flow of fuel and auxiliary air from the high-pressure tank was started. At the same time, the DAS starts collecting all data, and $0.5 \mathrm{~s}$ later the ignition system was initiated. The open flame at the end of the detonation chamber was usually initiated a few seconds before each experiment. Each experiment was also recorded by a camera from the window of the control room. A schematic diagram of the test stand is presented in Fig. 1, a schematic diagram of the annular detonation chamber is presented in Fig. 2, while a view of the experimental test stand is shown in Fig. 3.

\section{Experimental results}

Experiments were conducted for commercially available gasoline and Jet-A mixtures with air. Typical results from the conducted experiments are presented in Figs. 4, 5, 6a and Figs. 8 and 9. Strong evidence of a single wave stable rotating detonation with a velocity of $1045 \mathrm{~m} / \mathrm{s}$ can be observed in Fig. 4. But in some other experiments, shown in Fig. 5, two counter-rotating waves with slightly higher velocity were recorded.

For gasoline-air mixtures the longest run lasts about $4 \mathrm{~s}$ (Fig. 6), and the picture of the detonation chamber with visible flame, outside the chamber, is presented in Fig. 7. The observed drift of the pressure signal during 4-s operation time is due to the heating of the Kistler pressure transducer. For this reason a longer period of cooling the detonation chamber between successive experiments must be maintained in order to allow the pressure transducer to cool down.

For the case of Jet-A mixture with air, up to now we have been able to obtain quasi-stable detonation propagating with velocity of $1096 \mathrm{~m} / \mathrm{s}$ (Fig. 8), but it was also possible to record stable detonation in the mixture with compositions closer to stoichiometric (Fig. 9). In this case, the measured rotating detonation velocity is equal to $1170 \mathrm{~m} / \mathrm{s}$, which is about $65 \%$ of the theoretical Chapman-Jouget velocity for this mixture. As it can be seen from the experimental results, continuously rotating detonation, at tested conditions, can propagate in stable or unstable mode depending on the mixture supply rate as well as on the equivalence ratio. With the present arrangement, gasoline as well as Jet-A in a mixture 


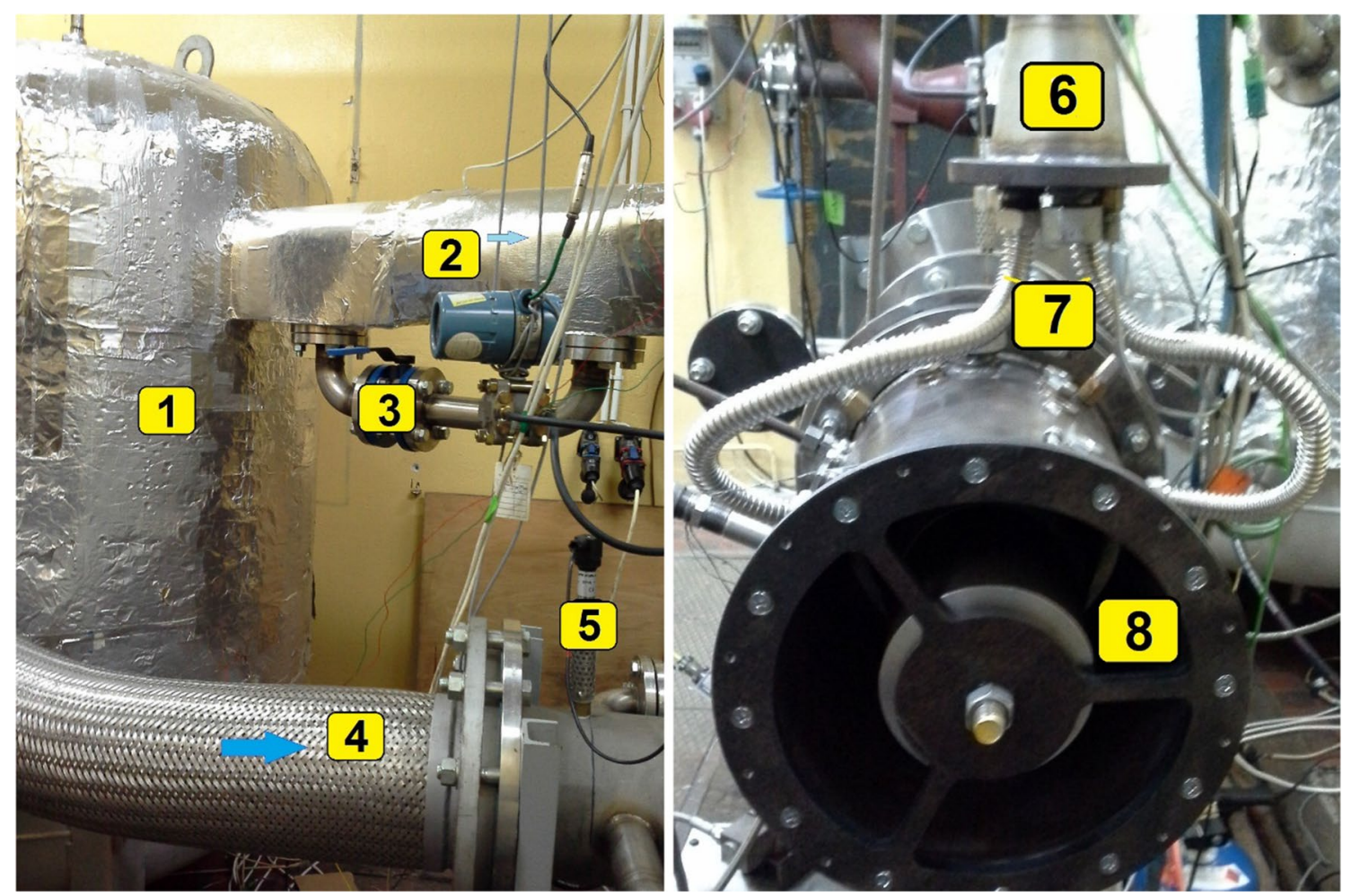

Fig. 3 View of the experimental test stand: 1-Compressed air reservoir; 2-Injector supply pipeline; 3-By-pass valve; 4 -Main air pipeline supplying the detonation chamber; 5-Pressure sensor; 6-Mixing chamber; 7-Pipes supplying rich mixture to the detonation chamber; 8 -Exhaust from detonation chamber

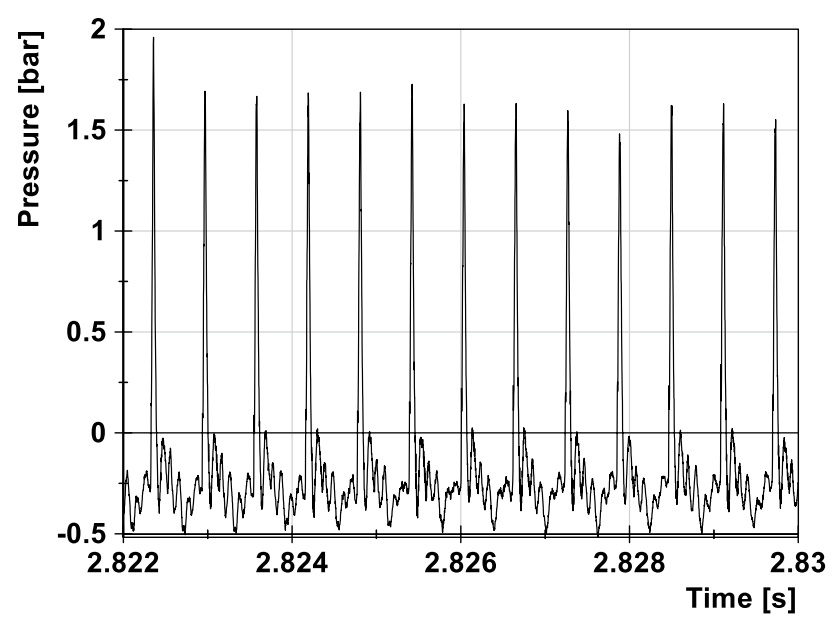

Fig. 4 Measured pressure variation in annular detonation chamber for gasoline-air mixture of equivalence ratio $(\phi)$ equal to 1.14 total mass flow rate equal to $361 \mathrm{~g} / \mathrm{s}$, and measured rotating detonation velocity equal to $1045 \mathrm{~m} / \mathrm{s}$

with air can detonate without any addition of gaseous hydrogen or other substances which may make mixture more sensitive to detonation combustion.

The observed detonation velocity deficit is due to a few reasons. As it was already shown by numerical simulation

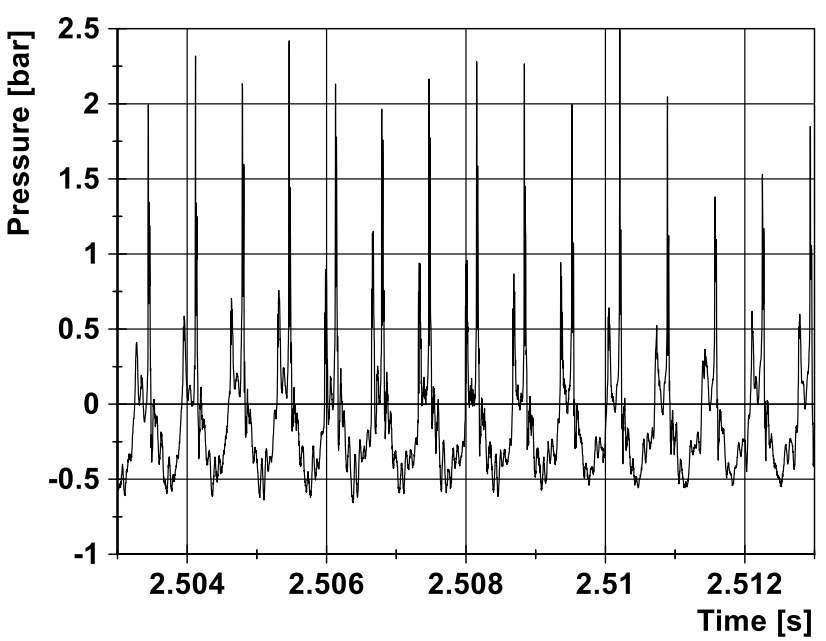

Fig. 5 Measured pressure variation for gasoline-air mixture of equivalence ratio $(\phi)$ equal to 1.13 , total mass flow rate of air equal to $355 \mathrm{~g} / \mathrm{s}$, and rotating detonation wave velocity equal to $1110 \mathrm{~m} / \mathrm{s}$

some fuel is burning in deflagration mode before the arrival of the detonation front, so less heat is released in the detonation zone [8-11]. Additionally, there are heat losses from the reaction zone to the wall as well as momentum losses. Non-perfect mixing within a short 
(a)

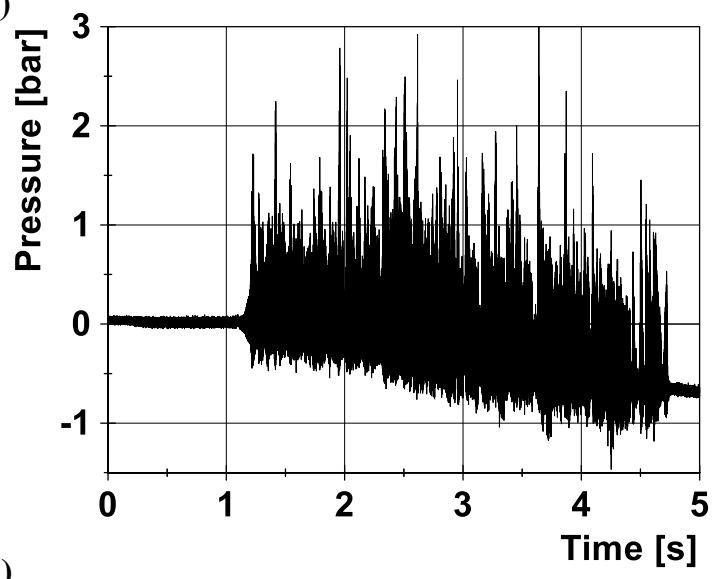

(b)

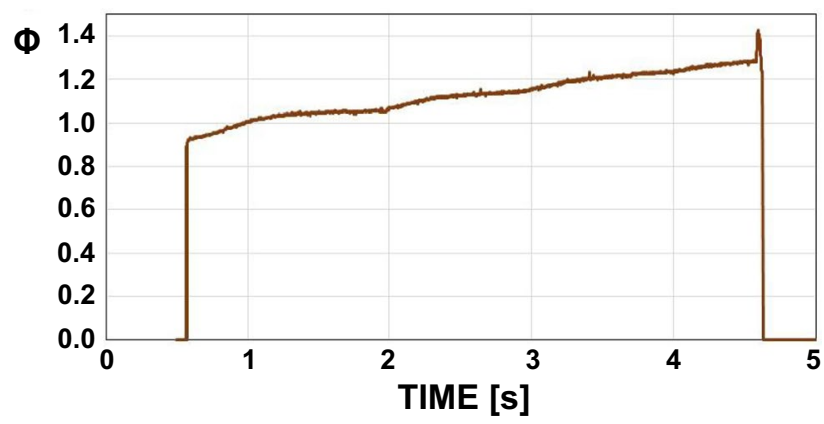

Fig. 6 Variation of pressure (a) and equivalence ratio $\phi$ (b) during tests of gasoline-air mixture distance of evaporated fuel with the main stream of air is another reason for the deficit of detonation velocity as compared to the ideal value calculated by the NASA code [12]. To decrease these losses more detailed theoretical and experimental research must be conducted.

\section{Discussion and conclusions}

On the basis of the conducted experiments it is clearly seen that if the fuel-air mixture is properly prepared, stable continuously rotating detonation in an annular detonation chamber can be achieved. Evaporation of liquid fuel before injection to the detonation chamber is most important to provide appropriate conditions to support stable detonation in the chamber. Obviously, chamber/channel dimensions, initial pressure, and rate of supply mixtures also play a crucial role in supporting stable continuously rotating detonation. At these research conditions, stable detonation was achieved not only for gasoline-air mixtures but also for Jet-A-air mixtures in a narrow range of mixture equivalence ratios, but nothing fundamental stands in the way of accomplishing stable, continuously rotating detonation in annular chambers of turbine, turbojet, or ramjet engines operating on typically available jet fuels, and in a wider range of mixture equivalence ratios. However, to develop such a system for commercial applications it is still necessary to design and test a compact system which will ensure injection of evaporated fuel to detonation chamber of gas turbines or aeronautical engines. This research opens the road to real applications of liquid fuels to air-breathing detonation propulsion.
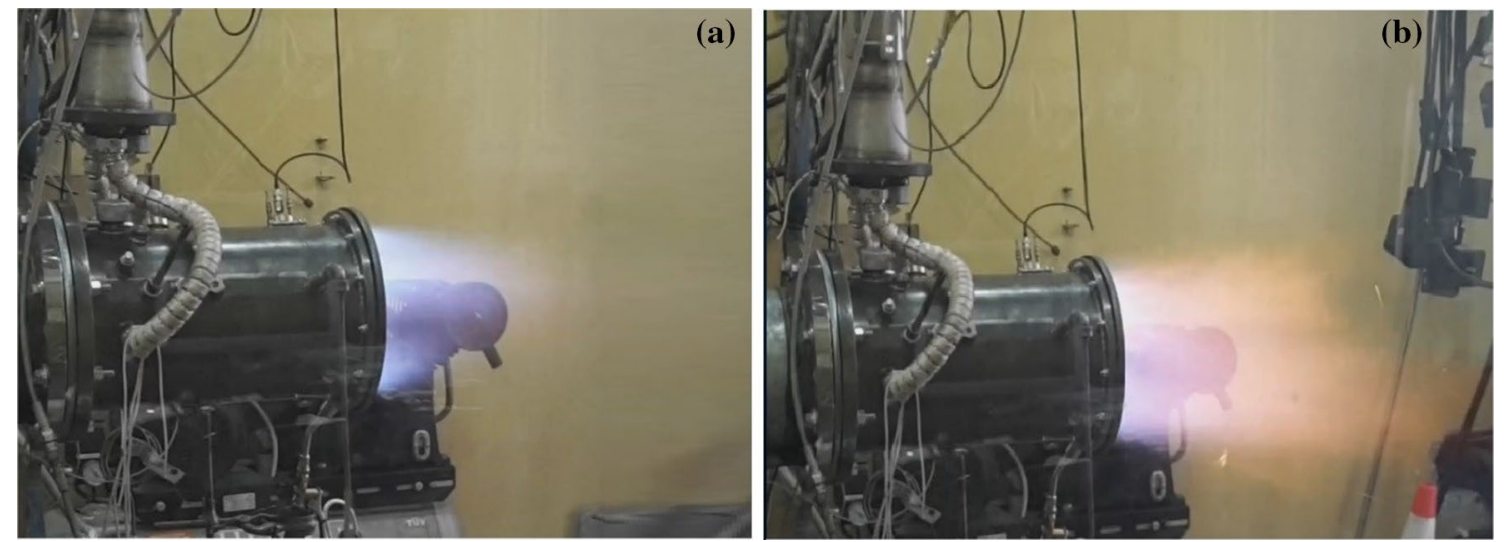

Fig. 7 Typical picture of the flame emerging from the rotating detonation chamber: at the beginning of the test-equivalence ratio $\phi \approx 1.0(\mathbf{a}) ;$ at the end of the test $-\phi>1.2(\mathbf{b})$; images were taken during the test recorded in Fig. 6 


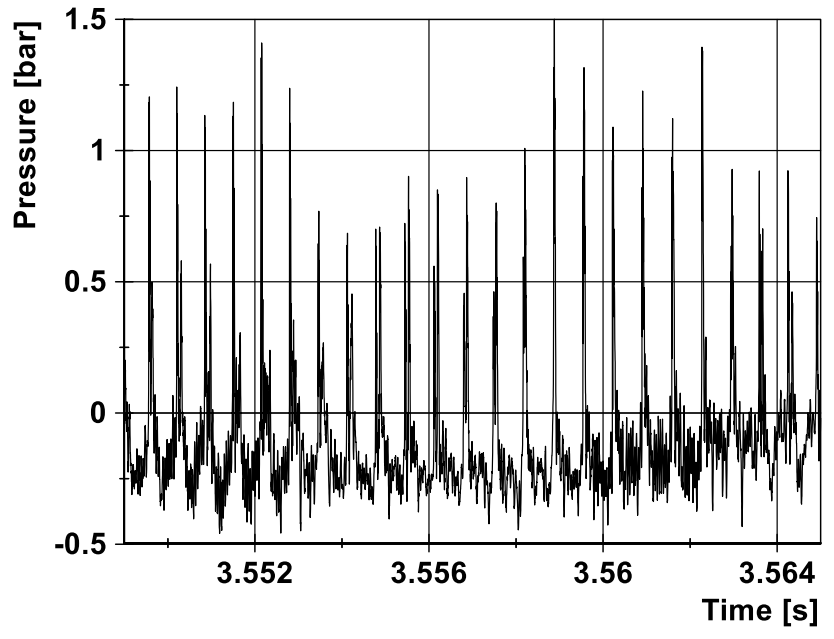

Fig. 8 Measured pressure variation for Jet-A-air mixture of equivalence ratio $(\phi)$ equal to 1.06 , total mass flow rate of air equal to $286 \mathrm{~g} / \mathrm{s}$, and rotating detonation wave velocity equal to $1096 \mathrm{~m} / \mathrm{s}$

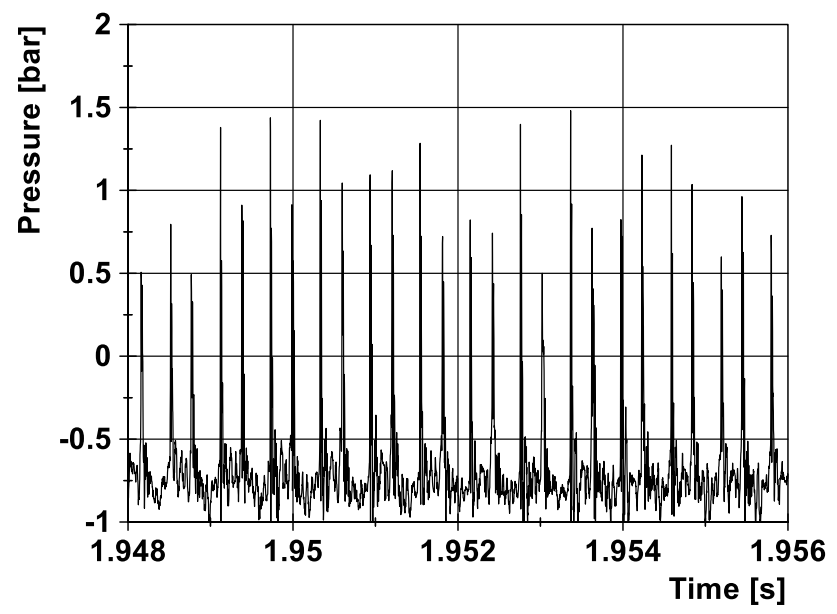

Fig. 9 Stable rotating detonation in the mixture of Jet-A-air at equivalence ratio $\phi$ equal to 1.17 , total mass flow rate of air equal to $391 \mathrm{~g} / \mathrm{s}$, and rotating detonation velocity equal to $1170 \mathrm{~m} / \mathrm{s}$

Acknowledgements This research was supported by an internal grant from the Łukasiewicz Research Network-Institute of Aviation, Grant No. SNLP 21928.

Open Access This article is licensed under a Creative Commons Attribution 4.0 International License, which permits use, sharing, adaptation, distribution and reproduction in any medium or format, as long as you give appropriate credit to the original author(s) and the source, provide a link to the Creative Commons licence, and indicate if changes were made. The images or other third party material in this article are included in the article's Creative Commons licence, unless indicated otherwise in a credit line to the material. If material is not included in the article's Creative Commons licence and your intended use is not permitted by statutory regulation or exceeds the permitted use, you will need to obtain permission directly from the copyright holder. To view a copy of this licence, visit http://creativecommons.org/licenses/by/4.0/.

\section{References}

1. Shen, P.I., Adamson, T.C., Jr.: Theoretical analysis of a rotating two-phase detonation in liquid rocket motors. Acta Astronaut. 17, 715-728 (1972)

2. Nicholls, A.J., Cullen, R.E.: The feasibility of a rotating detonation wave rocket motor. The Univ. of Mich., ORA Report 05179$1-\mathrm{P}(1962)$

3. Wolański, P.: Detonative propulsion. Proc. Combust. Inst. 34, 125-158 (2013). https://doi.org/10.1016/j.proci.2012.10.005

4. Wolański, P.: Application of the continuous rotating detonation to gas turbine. Appl. Mech. Mater. 782, 3-12 (2015)

5. Wolański, P.: Research on the application of continuous rotating detonation to gas turbine. J. Polish Am. Sci. Technol. 9, 15-48 (2015)

6. Wolański, P., Kalina, P., Balicki, W., Rowiński, A., Perkowski, W., Kawalec, M., Łukasik, B.: Development of gasturbine with detonation chamber. In: Li, J.-M. et al. (eds.) Detonation Control for Propulsion, pp. 23-37. Springer (2018). https://doi.org/10.1007/ 978-3-319-68906-7_2

7. Wolański, P., Balicki, W., Kalina, P., Perkowski, W.: Injector of an Over-Enriched Fuel and Air Mixture to the combustion Chamber of Internal Combustion Engines. EU Patent Appl. No. 18185203.9 and US Patent Appl. No. 16/044,387 (2018)

8. Nordeen, C.A., Schwer, D., Schauer, F., Hoke, J., Cetegen, B., Barber, T.: Thermodynamic modeling of a rotating detonation engine. 49th AIAA Aerospace Science Meeting including the New Horizons Forum and Aerospace Exposition, Orlando, FL, AIAA Paper 2011-803 (2011). https://doi.org/10.2514/6.2011-803

9. Nordeen, C.A.: Thermodynamics of a rotating detonation engine. Doctoral Dissertation, University of Connecticut Graduate School (2013).

10. Paxson, D.E.: Impact of an exhaust throat on semi-idealized rotating detonation engine performance. 54th Aerospace Sciences Meeting, San Diego, CA, AIAA Paper 2016-1647 (2016). https:// doi.org/10.2514/6.2016-1647

11. Kaemming, T., Fotia, M.L., Hoke, L., Schauer, F.: Thermodynamic modeling of a rotating detonation engine through a reduced order approach. J. Propul. Power 33(5), 1170-1178 (2017). https:// doi.org/10.2514/1.B36237

12. McBride, B., Stanford, G.: NASA-Glenn Chemical Equilibrium Program CEA2, May 21, 2004. NASA RP-1311, Part I (1994); NASA RP-1311, Part II (1996)

Publisher's Note Springer Nature remains neutral with regard to jurisdictional claims in published maps and institutional affiliations. 